\title{
Physiological aspects of somatic polyembryogenesis in suspension cultures of conifers
}

\author{
D.J. Durzan
}

Department of Environmental Horticulture, University of California, Davis, CA 95616, U.S.A.

\section{Introduction}

Somatic polyembryogenesis (SPE) is a new cell culture technology that needs to be distinguished from somatic embryogenesis and other forms of regeneration (cf. Durzan, 1988a). SPE, involving the reconstitution of multiple embryos by cleavage or budding of a proembryo, is one of 3 categories of regeneration recognized by Sinnott (1960). It is one of 4 broad categories of polyembryogenesis (see Table 1). Process control of SPE in cell suspension cultures for the multiplication of tree crops has been reviewed by Durzan (1988a, b) and Durzan and Gupta (1988). Using cell suspension cultures of embryonal-suspensor masses (ESMs) from loblolly pine and Douglas fir, morphogenic protoplasts have been prepared that enable the recovery of somatic embryos and the transient expression of a foreign gene (luc) (Gupta and Durzan, 1987a; Gupta et al., 1988). Somatic embryos have also been recovered from cryopreserved ESMs (Gupta et al., 1987). In this review, several recently recognized phy-

Table 1. Products produced by polyembryogenesis as a form of agamospermy (Durzan, 1988a).

\begin{tabular}{ll}
\hline Type & Product attributes \\
\hline Simple & $\begin{array}{l}\text { Several zygotes, but one embryo from one zygote to produce groups of embryos } \\
\text { of fraternal type (not clones) }\end{array}$ \\
Cleavage & $\begin{array}{l}\text { Asexual reconstitution of transplanted zygotic embryos (embryonal-suspensor } \\
\text { masses) yielding an identical type (clones). One or more groups of a given } \\
\text { fraternal type are possible. Cleavage and budding are similar except in terms of } \\
\text { source and topological orientation of the reconstituted embryos. }\end{array}$ \\
Sporophytic & $\begin{array}{l}\text { Adventitious embryos arise by budding from the nucellus (clones of the sporo- } \\
\text { phyte) or from differentiated embryonal cells (clones of the new generation). }\end{array}$ \\
Gametophytic & $\begin{array}{l}\text { The haploid embryos arise from transformed female gametophytes, i.e., they are } \\
\text { products of meiosis and are not considered clones. If embryos become diploid, } \\
\text { they are not identical to the parental tree. }\end{array}$ \\
\hline
\end{tabular}




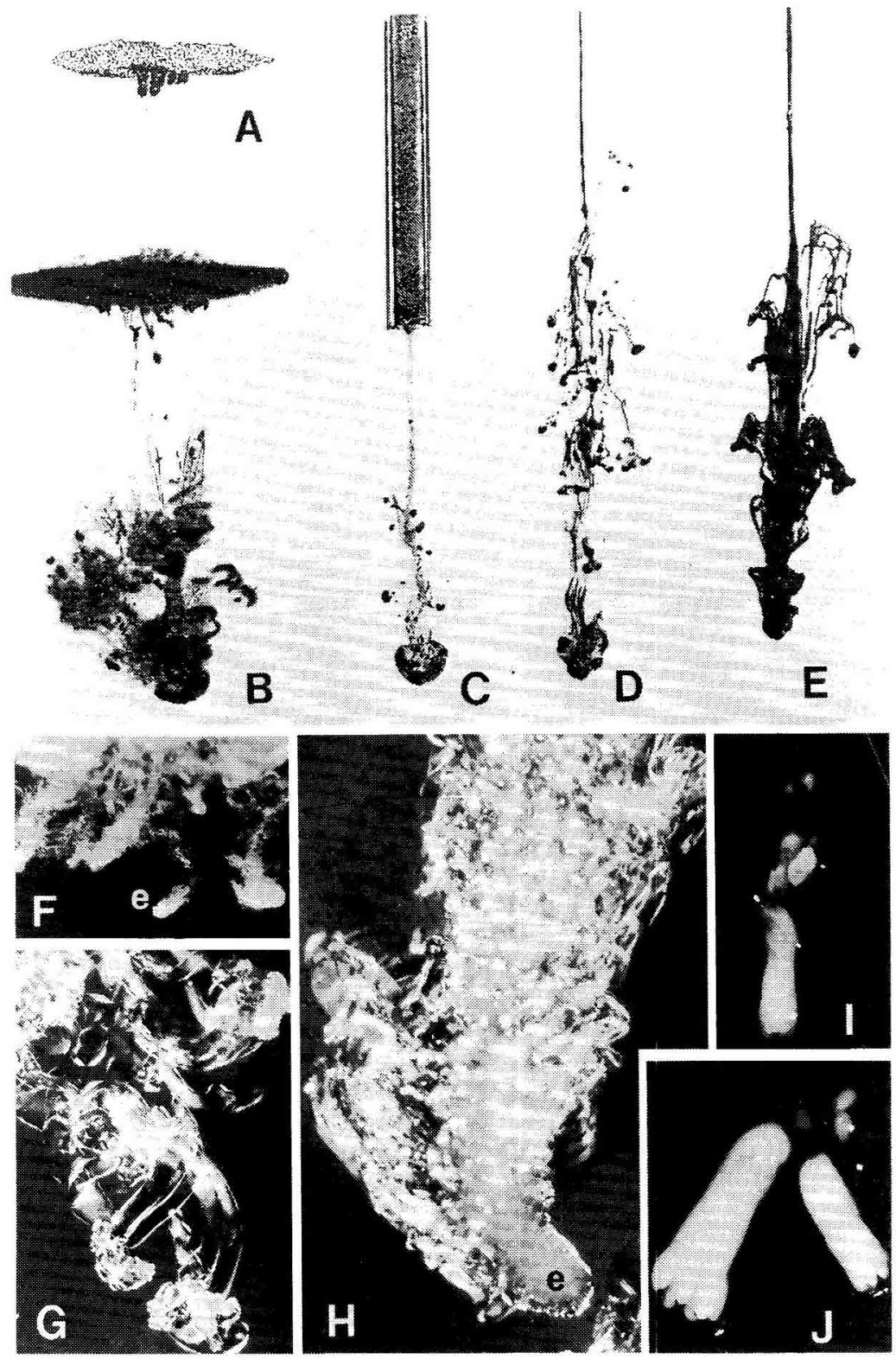

Fig. 1. Vertical density currents created by the fall of dense particles (A-E redrawn from Bradley, 1965) in a viscous fluid and cells of the embryonal-suspensor mass $(\mathbf{F}-\mathbf{J})$ in a viscous fluid. A. Several small vertical density currents start to form on the underside of a cloud of particles in water overlaying a saline solution. B. Descent of solid particles, creating a vertical density current with fragmented clouds less dense than the heaviest cloud. C. Vertical density current with a bulbous cap at the bottom that is starting to flare and form a torus. D. A later stage of vertical density current formation in which stream-tubes in the current start to constrict and enlarge to form nodes. E. Another later stage of stream-tube development, showing in the lower part a succession of caps through 
siological aspects of SPE in conifers (Douglas fir, Pseudotsuga menziesii; Norway Spruce, Picea abies; loblolly pine, Pinus taeda; and sugar pine, $P$. lambertiana) are presented.

\section{Physicochemical aspects of polyem- bryogenesis}

In the evolution of the seed habit, fertilization has become independent of water as a medium for the process (Heslop-Harrison, 1983). Furthermore, the development of the zygote of gymnosperms occurs in darkness and in a viscous, mucilaginous fluid. This fluid has interesting dynamic properties, with physicochemical implications for the polyembryonic processes. The fluid surrounds the zygotic proembryo as it grows and develops within the erosion duct of the nourishing female gametophyte or on a semi-solid medium. Suspension cultures of the ESM also contain this mucilage, which contributes to the viscosity of the liquid medium.

The mucilage and cells of the ESM have an affinity for water. This affinity was exploited by earlier investigators who presoaked seeds to facilitate the removal of embryos from bracts of cones (cf. Dogra, 1967).

\section{Fluid dynamics: fractal aspects of streak lines}

ESMs, transplanted just after fertilization onto agar plates with plant growth regulators, proliferate in darkness with the production of a clear, mucilaginous fluid. The viscosity of this mucilage is indicated by a fluid bridge when forceps are used to remove some of the cells. The viscous fluid can be removed and studied with reference to known phenomena in fluid dynamics (Batchelor, 1967). Among physicochemical properties displayed by the fluid are streak lines, i.e., patterns created by inanimate particles settling in the fluid (ct. Fig. 1A-E). In suspension cultures, where viscosity is increased by high levels of sucrose, myoinositol and casein hydrolysate, streak lines reflect the characteristically polyembryonic shapes of ESMs (Fig. $1 \mathrm{~F}-\mathrm{J}$ ).

The factor that estimates the relative importance of non-viscous (inertial) and viscous forces created by settling particles or cells acting on the fluid is the Reynolds number, $R$. $R$ is based on the length of flow, density and viscosity of the medium. Surface tension and the heterogeneity of particles or cells in the inoculum (ESM) are also factors.

According to Batchelor (1967), when $R$ equals one, the viscous, inertial and pres-

\footnotetext{
which the stream-tube passes. The current also shows the peripheral formation of new caps. F. The emergence of somatic embryos produced by polyembryogenesis from an ESM transplanted onto the surface of an agar medium is not unlike the start of vertical density current formation in $\mathbf{A}$ and $\mathbf{B}(x 13)$. G. Fragmentation of a loblolly pine polyembryonic mass in cell suspension culture, as viewed with polarized light, compares with $B$ above ( $x$ 24.7). H. A developing loblolly pine embryo (e) with a large suspensor, as viewed under polarized light. The suspensor morphologically resembles the flow patterns (stream lines) of a solid sphere falling in a viscous fluid ( $x$ 44.2). I. Polyembryonic mass, excised from the erosion zone of sugar pine and placed on an agar surface, shows the heaviest embryo at the bottom and the lighter cleavage and budding products on top. Multiple embryos are produced by cleavage and budding polyembryogenesis on a 'thread' of cells in the ESM (x 6.5). J. Embryos transplanted from sugar pine seeds continue to develop and can be rescued, i.e., regenerated, by the process of reconstitution (Sinnott, 1960) and multiplied by somatic polyembryogenesis (Durzan, 1988a) (x 7.8).
} 
sure forces in the system contribute to the motion of the fluid around descending particles. When $R$ is less than one, inertial forces are negligible. We can postulate that similar physicochemical forces are imposed on embryogenic cells of transplanted embryonal-suspensor masses in suspension culture under the influence of gravity. These forces are imposed on the histogenic algorithm and translated into the ontogeny that is characteristic for each conifer type (Durzan, 1988a). The end result is that proembryonal developmental patterns mimic, with their dense proembryonal cells and their bouyant elongated capillary-like suspensors, the fractal dynamic forces found in viscous fluids in suspension cultures, as revealed by streak lines and vertical density currents. We can now study these forces in artificial systems outside the seed. The expectation is that new principles will arise for the improved design of 'artificial seeds', especially in relation to suspended nutrients and amino acid chelates in the mucilage.

\section{Verticai density currents}

Vertical density currents in viscous fluids are created by particles and/or cells settling under the influence of gravity. With vertical density currents, some cells may fall much more rapidly than settling according to Stoke's law (Bradley, 1963). This phenomenon occurs in limnology and is evident in other natural events (Bradley, 1963; Thompson, 1942).

Vertical density currents occur in closed systems where the fluid is incompressible, i.e., its density is not affected by changes in pressure. Such currents are found in suspension cultures and possibly on a micro scale in the erosion duct of seeds. Inside cells, currents may also be displayed by nuclei and ergastic materials during the protoplasmic streaming of embryonal tube cells in the budding process.

As cells settle in a viscous culture medium, the fall is compensated by a rising current from the bottom. In static suspension cultures of an ESM, a critical viscosity is required to create vertical density currents by proembryos falling under the influence of gravity. By contrast, proembryos in the erosion duct of a seed maintain contact with cells of the female gametophyte that are being digested for nutrients. Under static conditions and in highly viscous culture media, the fall of particles, cells and isolated proembryos is slowed to the amount of energy required to overcome the viscous resistance to flow and shearing stress. The resultant drag establishes the direction of the falling material.

As organelles, protoplasts and cells fall in a vertical density current, a flow pattern arises, whereby the heavier particles form a bulbous cap at the lower end, not unlike the dominant proembryo in an embryonalsuspensor mass. The shape of the cap contributes to the flaring, involution and surface discontinuities that emerge. These forces create a sheath or boundary layer for the stream tube.

Stream lines may appear irregular and fractal, reflecting the constrictions and enlarging nodes of the settling particles and cells (Batchelor, 1967). Rings on eitheir side of the stream arise from the peripheral breakdown (instability) of cell masses.

Shearing stresses are associated with the property of viscosity (Kay and Nedderman, 1985). For somatic polyembryogenesis, the analogy is proposed that, at points of instability on the ESM created by shear stresses, new embryos could form by cleavage or budding. The analogy remains to be tested experimentally. Where 

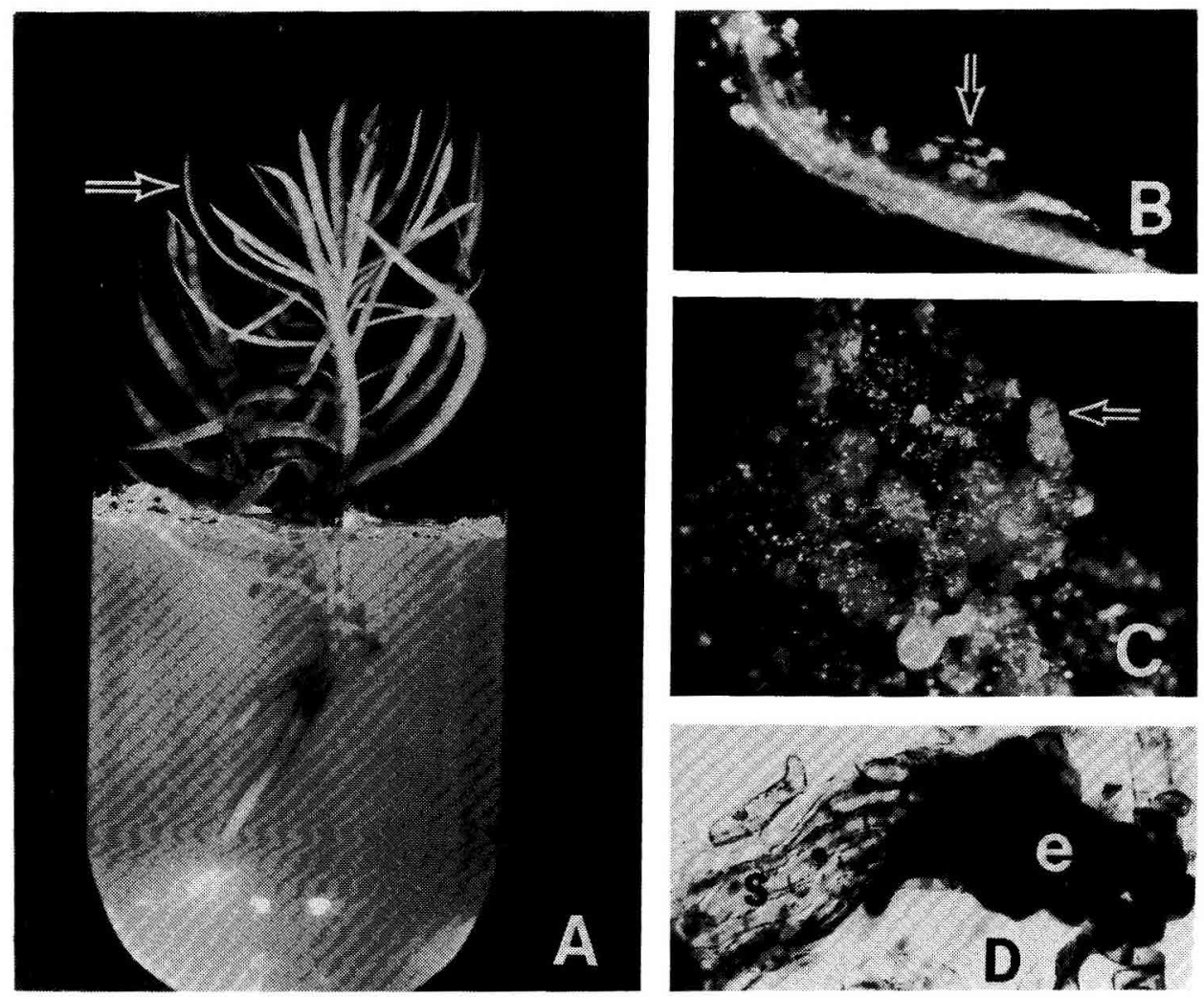

Fig. 2. The influence of a mucilaginous ESM on needles removed from rejuvenated and micropropagated shoots of a $60 \mathrm{yr}$ old Douglas fir tree (preliminary observations with P.K. Gupta). A. Micropropagated shoot serving as a source for explants (e.g., arrow) (cf. Gupta and Durzan, 1987c) (x 9.5). B. Explanted needle is covered with ESM mucilage (nurse culture) (arrow) on a $0.5 \mathrm{MS}$ medium with $450 \mathrm{mg} / \mathrm{l}$ glutamine, $500 \mathrm{mg} / \mathrm{l}$ casein hydrolysate, 100 $\mathrm{mg} / \mathrm{l}$ myoinositol, 2,4-D (5 $\mu \mathrm{M})$ and kinetin and BAP (2 $\mu \mathrm{M}$ each) for $6 \mathrm{wk}$ in darkness) (x 14.3). C. After 8-10 wk, somatic embryos (e.g., arrow) appear on the surface of the newly formed callus. Callus is created by exposure to the mucilage. The callus is then transferred to a medium having $50 \mu \mathrm{M} 2,4-\mathrm{D}$, kinetin and BAP (20 $\mu \mathrm{M}$ each). D. Recovery of the ESM after 10 wk reveals the production of a somatic embryo (e) with a suspensor (s), presumably originating from the explant in contact with the ESM. Markers are needed to differentiate the fates of cells derived from the callus and from the ESM. This can be done to a limited extent by taking an ESM from one species and exposing its mucilage to explants from another species. Morphological features of the regenerated embryos will indicate which type of embryony has been induced. If embryogenesis can be induced by this process, then embryos characteristic of the explant, rather than of the ESM, should be recoverable.

stresses are great, as in shake cultures with Erlenmeyer flasks, cells of the ESM tend to lignify (Gupta and Durzan, 1987b).

Settling particles in a viscous fluid form a torus at the front (Batchelor, 1967). A torus of particles may divide into 2 components, not unlike a cleaved proembryonal cell, at least under certain conditions (see Batchelor, 1967). However, I am not yet sure how far to compare the behavior of inanimate particles with polyembryonic systems in explaining the physicochemical processes underlying the histogenic algorithms. 


\section{Plant growth regulators in mucilage}

Nurse cultures, or contact of mucilaginous ESMs with explants from the same or different species, will promote morphogenetic activity in the ESM and/or in the explant (Fig. 2). The cause of this continued response is uncertain, but suggests that growth factors are found in the mucil- age. The growth factors contribute to the production of a callus and possibly can induce embryogenesis in cells of the explant. Moreover, when cells of the ESM are cultured in liquid medium, the mucilage can polymerize under the influence of plant growth regulators. Products of the polymerization can mimic shapes of the embryo (Fig. 3).
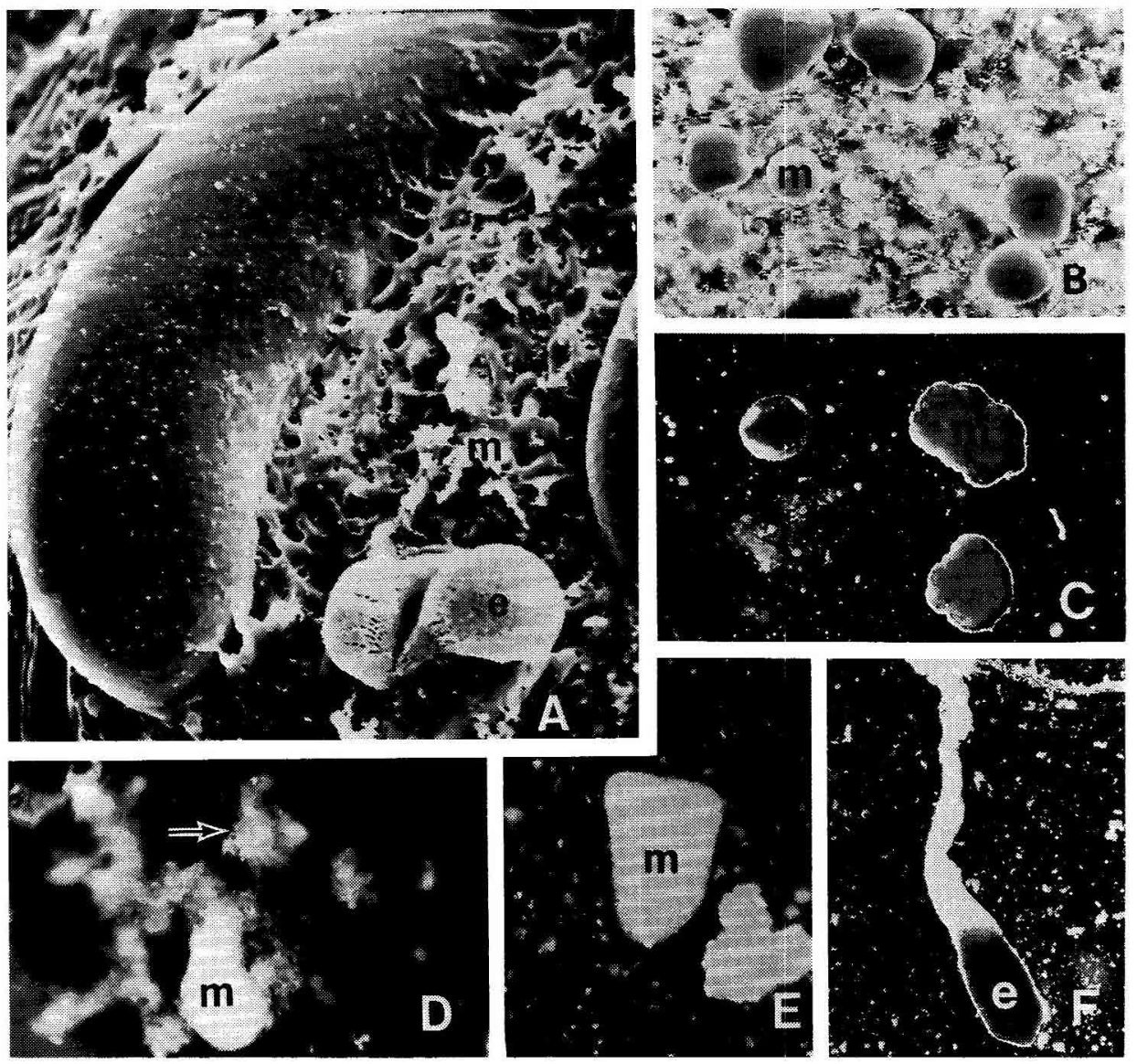

Fig. 3. Properties of the mucilaginous material in the ESM. A. Cells of the embryonal-suspensor mass protrude from the mucilage $(m)$, as revealed by cryopreparation and scanning electron microscopy (x 420). B. An ESM of Douglas fir, when grown in the presence of NAA. sometimes releases polymerized material into the medium $(x 14)$. C. The polymerized material stains red with acetocarmine $(x 14)$. D. ... and sometimes mimics the shape $(\mathrm{m})$ of somatic embryos (arrow points to cells of a suspended ESM) (x 14). E. Elongated, polymerized material $(\mathrm{m}) \mathrm{re}$ leased by cells derived from a cotyledon callus grown in cell suspension culture of Douglas fir $(x 14)$. F. Somatic embryo $(e)$ of Douglas fir with a suspensor. Note that the embryo also stains with acetocarmine $(x 17.5)$ 
Progress in understanding morphogenesis will depend upon the simplification of such physiological systems, better conditions for physicochemical measurements, improved methods for image analysis (e.g., Serra, 1982) and a better understanding of how abscisic acid and other plant growth regulators contribute to this process (Boulay et al., 1988; Durzan, 1987).

\section{References}

Batchelor G.K. (1967) In: An Introduction to Fluid Dynamics. Cambridge University Press, Cambridge

Boulay M.H., Gupta P.K., Krogstrup P. \& Durzan D.J. (1988) Conversion of somatic embryos from cell suspension cultures of Norway spruce (Picea abies Karst.). Plant Cell Rep. 7, 134-137

Bradley W.H. (1963) Vertical density currents. Science 150, 1423-1428

Dogra P.D. (1967) Seed sterility and disturbances in embryogeny in conifers with particular reference to seed testing and breeding in Pinaceae. Stud. For. Suec. 45, 1-97

Durzan D.J. (1987) Plant growth regulators in cell and tissue culture of woody perennials. Plant Growth Regul. 6, 95-112

Durzan D.J. (1988a) Somatic polyembryogenesis for the multiplication of tree crops. Biotech. Genet. Eng. Rev. 6, 339-376

Durzan D.J. (1988b) Process control in somatic polyembryogenesis. In: Molecular Genetics of Forest Trees, (Hällgren J.E., ed.), Frans Kempe Symp. 1988, Swedish Agric. Univ., Umea. pp. 147-186
Durzan D.J. \& Gupta P.K. (1988) Somatic embryogenesis and polyembryogenesis in conifers. Adv. Biotech. Processes 9, 53-81

Gupta P.K. \& Durzan D.J. (1987a) Somatic embryos from protoplasts of loblolly pine proembryonal cells. Bio/Technology 5, 710-712

Gupta P.K. \& Durzan D.J. (1987b) Biotechnology of conifer-type somatic polyembryogenesis and plantlet regeneration in loblolly pine. Bio/Technology 5, 147-151

Gupta P.K. \& Durzan D.J. (1987c) In vitro establishment and multiplication of juvenile and mature Douglas fir and sugar pine. Acta Hortic. $212,483-487$

Gupta P.K., Dandekar A.M. \& Durzan D.J. (1988) Somatic proembryo formation and transient expression of a luciferase gene in Douglas fir and loblolly pine protoplasts. Plant Sci. 58, 85-92

Gupta P.K., Durzan D.J. \& Finkle B.J. (1987) Somatic polyembryogenesis in embryogenic cell masses of Picea abies (Norway spruce) and Pinus taeda (loblolly pine) after freezing in liquid nitrogen. Can. J. For. Res. 17, 1130-1134

Heslop-Harrison J. (1983) The reproductive versatility of flowering plants: an overview. In: Strategies of Plant Reproduction, (Meudt W.J., ed.), Barc Symp. No. 6, Allanheld, Osmun, Totowa. pp. 3-18

Kay J.M. \& Nedderman R.M. (1985) In: Fluid Mechanics and Transfer Processes. Cambridge Univ. Press, Cambridge

Serra J. (1982): In: Image Analysis and Mathematical Morphology. Academic Press, New York

Sinnott (1960) In: Plant Morphogenesis. McGraw Hill, New York

Thompson D.W. (1942) In: On Growth and Form, Vol. 1. Cambridge Univ. Press, Cambridge 